\title{
Analysis of Micro Cracks and Die Erosion in Die Casting
}

\section{BHASKAR ( $\square$ mbhaskar0210@gmail.com )}

MVJCE: MVJ College of Engineering https://orcid.org/0000-0002-8465-5797

\section{Tamil selvam nalluswamy}

MVJCE: MVJ College of Engineering

\section{Original Article}

Keywords: chemistry, die casting, die surface roughness, erosion, injection pressure, soldering, temperature

Posted Date: May 10th, 2021

DOI: https://doi.org/10.21203/rs.3.rs-495892/v1

License: (c) (i) This work is licensed under a Creative Commons Attribution 4.0 International License. Read Full License 


\title{
Analysis of micro cracks and die erosion in die casting
}

\author{
M.Bhaskar, Professor, MVJ College of Engineering, Bangalore, India. \\ Tamil Selvam Nalluswamy, Assistant professor, MVJ College of Engineering, Bangalore, India. \\ Corresponding author mail id: $\underline{\text { mbhaskar0210@gmail.com }}$
}

\begin{abstract}
:
Die soldering is challenging issue on die life and casting quality in High Pressure Die Casting (HPDC) Industry. It increases die down time which causes increasing production cost per piece. Die soldering can be tackled by surface heat treatment operations like gas nitriding and other PVD coatings. Used and scraped die is selected from the die casting industry for investigation of die soldering issue. Chemical distribution of elements and surface condition of affected die soldering zone is investigated. The study reveals that, there are abundant micro cracks, micro holes and micro cavities at soldering portion. The radius of micro holes is about $0.25 \mu \mathrm{m}$ and the radius of macro holes is about $8 \mu \mathrm{m}$. The die inserts are made up of H13 die steel and LM24 Aluminum alloy is used for casting operation. At the die soldering cross section region, distribution of aluminum and die soldering mechanism and its causes studied. The die soldering mechanism is classified as chemical, physical, mechanical and mixed soldering. The soldering phenomena have been researched based on die temperature and its chemistry, metal temperature and its chemistry, injection pressure and its velocity, and die surface roughness. The spread and formation of die soldering on used and scraped die is also discussed in this article.
\end{abstract}

Keywords: chemistry; die casting; die surface roughness; erosion; injection pressure; soldering; temperature.

\section{Introduction:}

The production cost per piece depends on the die life. Studies shows that normal die life varies from 25000 cycles to 250000 cycles depending upon the design and complexity of the die (1) (2) (3) (4) (5). The production cost per piece can be reduced by increasing the die life. Die life is considered as total number of castings produced before its failure. Die may fail due to any one or combination of the following reasons like heat checks, chemical attack, soldering, mechanical erosion, thermal fatigue and mechanical stresses. Heat checking and die soldering are the two major factors which results in die failure (6) (7) (8) (9). Numerous past works have targeted principally on the heat checks (10) (11) (12) (13) (14). However, with the event of die casting trade, more and more consideration is being given to die bonding for a notable decrease in potency and productivity of die casting process. Recently some researchers have begun to review soldering mechanism by experimental work (15) (16) (17) (18) (19). However, die casting experiments in agreement with the particular production facilities will be terribly future and costly, so that some researchers have implemented many efficient experimental ways for work the attachment and the other phenomena within the facility (20) (21) (22) (23) (24). These strategies will be classified into 3 types: accelerated tests; friction welding and hot dip aluminizing. From the output of research work, the conclusions will be created that there are intermetallic compounds are produced within the die steel.

Different metallic element aluminum alloys presents a distinct bonding tendency towards the steel die. The bonding tendency of the casting to a given steel die will increase with the number of casting cycles (25) (26) (27) (28).

Soldering increases simply with rise in metal temperature, die temperature, injection velocity, injection pressure and failure of die surface coatings (29) (30) (31) (32) (33). Die surface treatments and PVD coatings will effectively scale back the incidence of soldering (34) (35) (36) (37). However the data of die soldering remains sensor activity. No theoretical approach has been finalized to investigate the consequences of method parameters on causing soldering problem.

In this article, the surface conditions of the die and the distribution of chemical elements of soldering zone have been studied to analyze the soldering mechanism. Theoretical analysis of the results of method parameters on inflicting soldering are administrated by connected theory. Finally, the generation and unfold of soldering in a given die portion with the die casting process have additionally been investigated. 


\title{
Experimental and Results:
}

Used and scraped die from the die casting company is taken to investigate the characteristics of the die soldering region. The die was employed to cast aluminum filter cover. The process parameters of the die are as follows:

\author{
Aluminum alloy grade: LM 24 \\ Metal temperature $\quad: 670-720^{\circ} \mathrm{C}$ \\ Die temperature $\quad: 200-250^{\circ} \mathrm{C}$ \\ Gate velocity $\quad: 35-40 \mathrm{~m} / \mathrm{sec}$ \\ Injection pressure $\quad: 80-100 \mathrm{MPa}$ \\ Solidification time : 10 seconds \\ Die coat/lubricant $\quad$ : Chem. trend water base die coat (1:100) ratio.
}

The die portion with soldered aluminum is cut off from the die to study the surface condition of the soldered die. The solder die part is dissolved with 15\% Caustic soda solution for 20 hours. Figure 1 (a) depicts the surface conditions of the soldered die at general position and (b) depicts the surface state near the gate location.
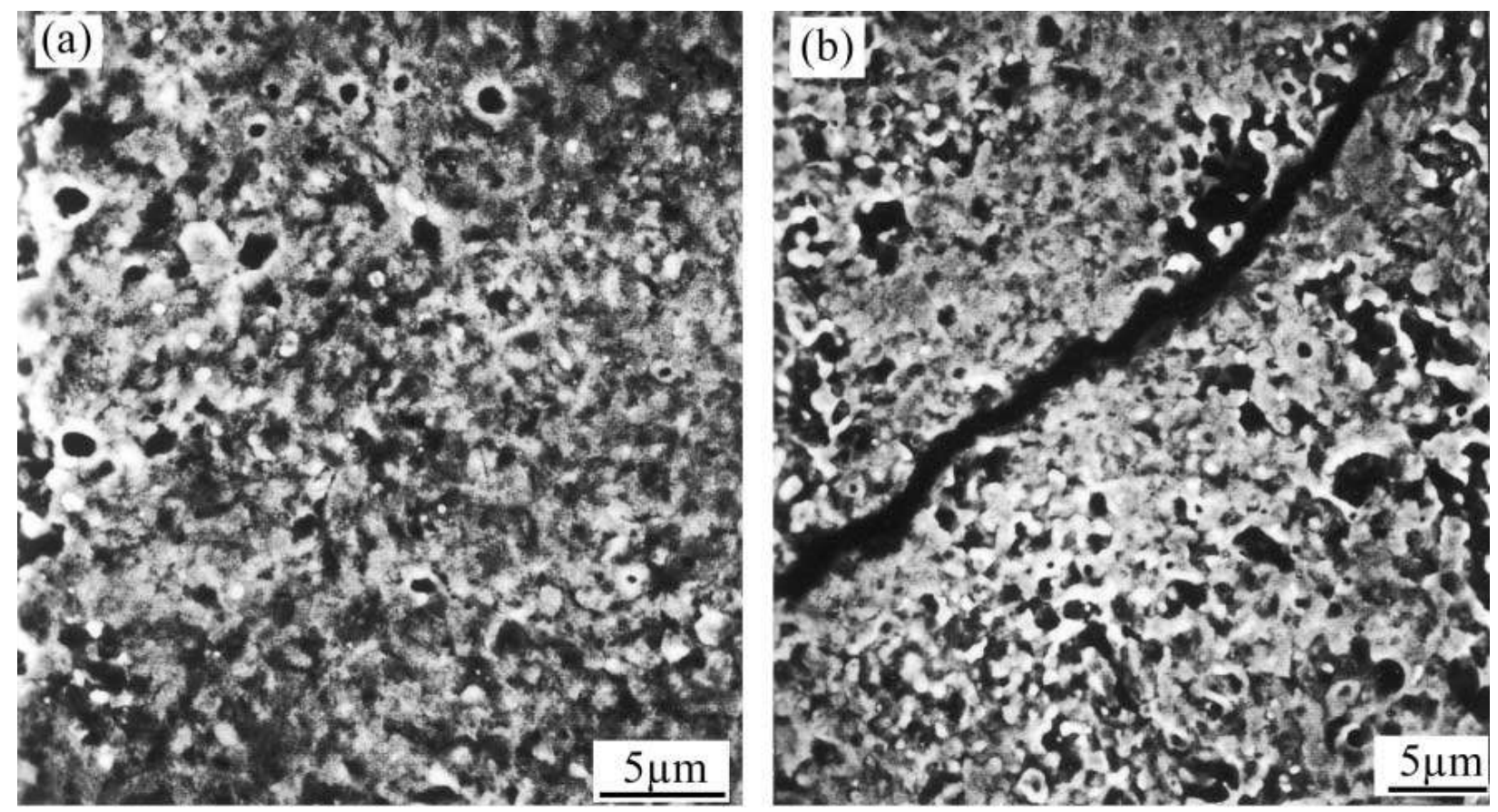

Figure 1. The surface condition of the soldered die: (a) general position in the die: (b) position near to gate location.

It is observed from Figure 1(a) that there exist various micro holes and micro cavities on the die surface. The radius of the tiny micro holes is about $0.25 \mu \mathrm{m}$ and the radius of large macro holes is about $8 \mu \mathrm{m}$. so the micro holes represents the character that intermetallic layers separates the die surface and therefore the micro cavities represents the character of small erosion. Die erosion near gate location is high while compare with general position in the die. There exist some cracks near the gate location as shown in Figure 1(b). Scanning electron microscopy (SEM) reveals the microanalysis of the soldering region as shown in Figures 2and 3. Figure 2. Depicts that there exit a straight interface between the die and soldered aluminum. It indicates the chemical reaction between the casting and the steel die. The soldering is predominantly physico- chemical bonding. When the liquid metal enters and solidifies curved cracks present in the die, strong mechanical interaction takes place and results in mechanical soldering as depicts in Figure 3. However, the cracks with tiny sizes are flared, the mechanical interaction caused by micro 
cavities and cracks are not strong enough that soldering occurs both chemical and mechanical action. Therefore soldering is classified as mechanical, physico- chemical and mixed soldering based on mechanism of soldering.
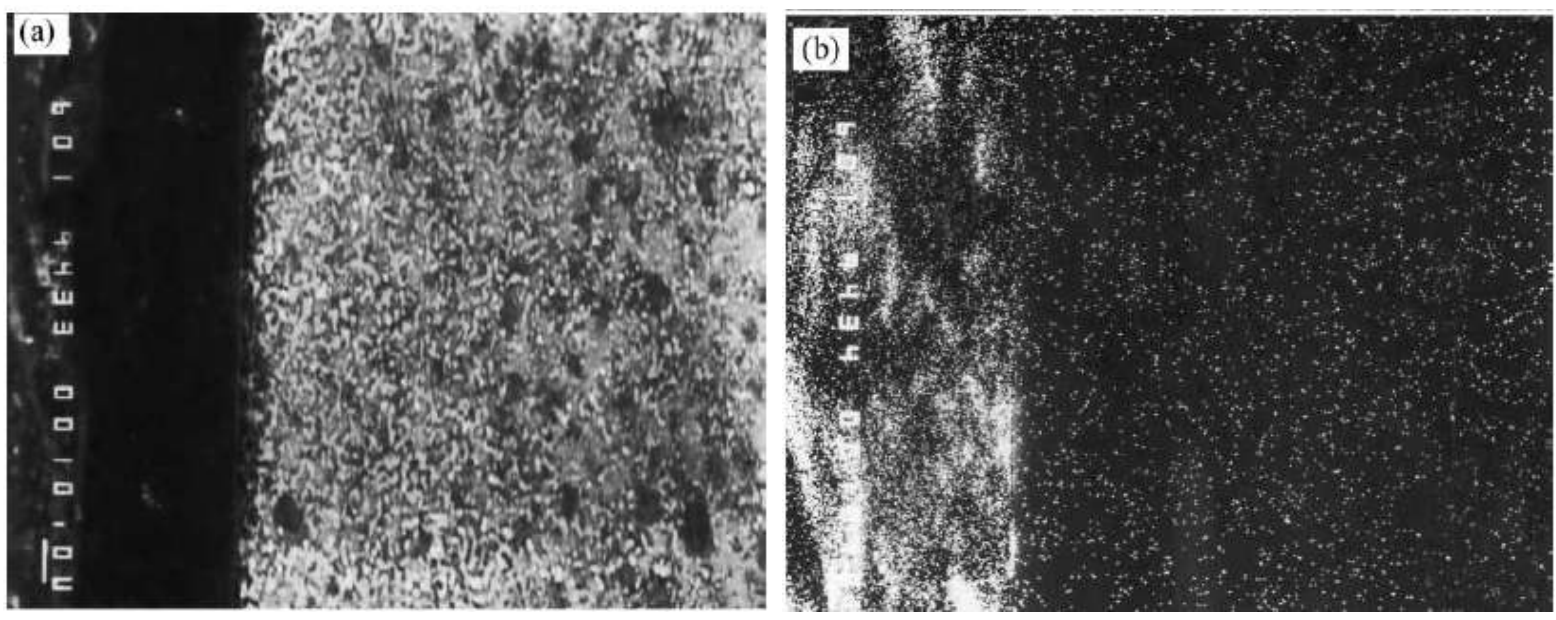

Figure 2. SEM analysis of physico- chemical soldering: (a) back scattered electron image (b) X-ray mapping of Al.

It is also noticed that most die surface parts with rich aluminum transition layers. The transition layer consists of intermetallic compounds which are the results of diffusion mechanism. The transition layer plays a vital role in soldering occurrences.
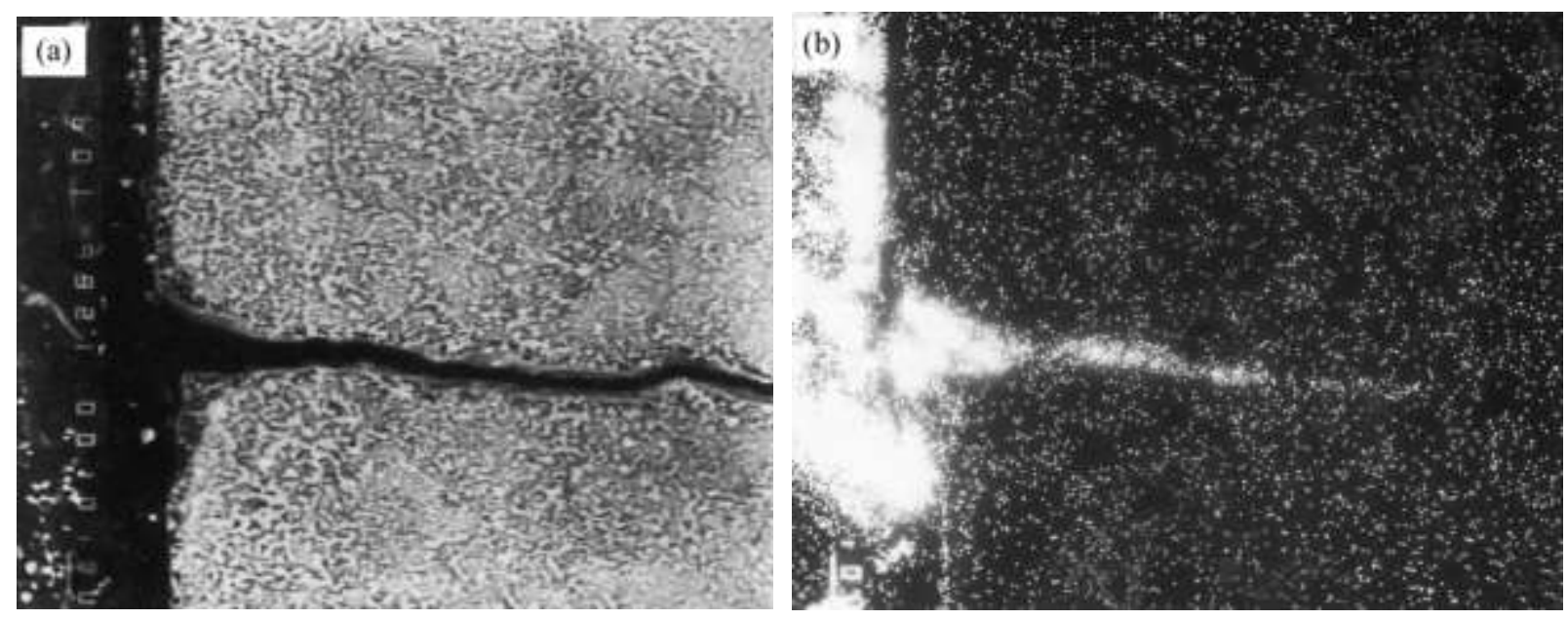

Figure 3. SEM analysis of Mechanical soldering: (a) back-scattered electron image: (b) X-ray mapping of Al.

During casting operation, molten metal is injected into the die cavity under high pressure and velocity. This activates atoms presents on the die surface and leads to breakage of atomic bonding. This result in aluminum atoms diffused with die atoms and forms atomic bonding. It is observed that most metallic bonds formed at high temperature still exist after solidification. Joint area is formed between the casting and die after casting cycle. Metallic bonds are produced, when there is interaction between atoms of molten aluminum and atoms of die steel. The atoms which gain constant activation energy are participated in bonding process. According to Maxwell-Boltsman law, the fraction of atoms in activation state to all interfacial atoms can be derived as:

$\mathrm{f}=\exp \left(-\frac{\Delta \mathrm{U}}{\mathrm{RT}}\right)$

Where $\Delta \mathrm{U}=$ constant activation energy of interaction. 
$\mathrm{f}=$ fraction of atoms. It is sure that fraction of atoms (f) is directly proportional to the ratio of real contact area and apparent contact area between the casting and die surface.

That is $\mathrm{f} \propto A r / A a$;

Now equation (1) becomes $\frac{\mathrm{Ar}}{\mathrm{Aa}}=\mathrm{A}_{0} \exp \left(-\frac{\Delta \mathrm{U}}{\mathrm{RT}}\right)$

When $\frac{\mathrm{Ar}}{\mathrm{Aa}}=1, \mathrm{~A}_{0}$ can be obtained as:

$\mathrm{A}_{0}=\exp \left(-\frac{\Delta \mathrm{U}}{\mathrm{RT} 0}\right)$

Where $\mathrm{T} 0=$ critical temperature, at which the casting bonds with the die. Then the equation (2) becomes

$\frac{\mathrm{Ar}}{\mathrm{Aa}}=\exp \left\{-\frac{\Delta \mathrm{U}}{\mathrm{R}}\left(\frac{1}{\mathrm{~T}}-\frac{1}{\mathrm{~T} 0}\right)\right\}$

The temperature of the liquid metal rises when it is injected on die surface under high velocity. An assumption is made that molten metal is injected on to the die surface at an angle of $\beta$ and velocity of $u$. The vertical component of the velocity of metal is known as kinetic energy. This energy with a given mass (m) is change into heat energy of the metal. The rise in temperature of the liquid metal due to increase in kinetic energy is given as:

$\Delta \mathrm{T}=\frac{\mathrm{U}^{2} \cos ^{2} \beta}{2 \mathrm{Cm}}$

Where $\mathrm{Cm}=$ specific heat of liquid aluminum. The gate area is constant for given die casting condition. The relation between injection pressure and filling velocity of liquid aluminum metal is expressed by Darcy equation:

$\mathrm{u}=\mathrm{C}_{\mathrm{d}} \sqrt{\frac{2 \mathrm{P}}{\rho \mathrm{M}}}$

Where $\mathrm{p}=$ injection pressure

$\rho \mathrm{M}=$ density of aluminum

$\mathrm{C}_{\mathrm{d}}=$ coefficient for cold chamber die casting and is equal to 0.8 .

The casting and die interface temperature can be expressed by the equation as:

$\mathrm{T}_{\mathrm{I}}=\frac{\mathrm{bMTM}+\mathrm{bmTm}}{\mathrm{bM}+\mathrm{bm}}$

Where $\mathrm{T}_{\mathrm{M}}=$ Melt temperature

$\mathrm{T}_{\mathrm{m}}=$ Die temperature

$b_{M}$ and $b_{m}=$ heat accumulation coefficient

The rise in interface temperature $\Delta \mathrm{T}_{\mathrm{i}}$ can be expressed as:

$\Delta \mathrm{T}_{\mathrm{i}}=\frac{\mathrm{bM}}{\mathrm{bM}+\mathrm{bm}} \Delta \mathrm{T}$

Considering equations (5)-(7), equation (3) can be written as

$$
\frac{A_{\mathrm{r}}}{A_{\mathrm{a}}}=\exp \left[-\frac{2 c \rho\left(b_{\mathrm{M}}+b_{\mathrm{m}}\right) \Delta U}{2 c \rho R\left(b_{\mathrm{M}} T_{\mathrm{M}}+b_{\mathrm{m}} T_{\mathrm{m}}\right)+R b_{\mathrm{M}} c_{\mathrm{d}}^{2} \cos ^{2} \beta P}+\frac{\Delta U}{R T_{0}}\right]
$$

Soldering of aluminum metal to the die surface is considered as adhesion of two different metals under pressure. The metallic bonds are formed by inter atomic forces exist between two metallic atoms caused by adhesive forces. The energies $\gamma \alpha$ and $\gamma \beta$ are required to break metallic bonds that exist between two solid metals $\alpha$ and $\beta$ in contact on unit area, whereupon the interfacial energy is recovered. The energy needed to create die soldering can be expressed as (38).

$\frac{\mathrm{Ar}}{\mathrm{Aa}} \geq \frac{2 \gamma \alpha}{\gamma \alpha+\gamma \beta-\gamma \alpha \beta}$

According to this expression, the ratio between real contact area and the apparent contact area between the casting and die is desperate factor which influences the soldering formation.

Figure 4. Depicts the effects of activation energy and temperature on $A_{r} / A_{a}$ where $\Delta U_{1}<\Delta U_{2}$. It is observed that the activation energy is vital element that influences the value of $A_{r} / A_{a}$, which is responsible for die soldering according 
to the energy criterion of soldering. At the same interface temperature, a rise in activation energy tends to reduce in number of atoms in the activity station and a tremendous reduction in the value of $\mathrm{A}_{\mathrm{r}} / \mathrm{A}_{\mathrm{a}}$. Therefore, a rise in activation energy causes to decrease in soldering effect of the casting to the steel die. This can be used to explain the effect of alloy composition and die surface chemistry which results in soldering. Because the activation energy of interaction of $\mathrm{Al}-\mathrm{Fe}$ is more than that of $\mathrm{Al}-\mathrm{Al}$. Increasing aluminum concentration on die surface results in increasing number of atoms that participated in soldering. Addition of iron $(\mathrm{Fe})$ upto $1.3 \mathrm{wt} \%$ in the aluminum alloy reduces soldering tendency during casting process. The reason behind that is the activation energy of $\mathrm{Al}-\mathrm{Fe}<$ than that of $\mathrm{Fe}-\mathrm{Fe}$. The separation of iron atoms from the liquid aluminum surface results in high concentration of iron atoms. The diffusion of iron atoms from die steel surface to the molten aluminum alloy can be prevented by high concentration of iron atoms in the alloy itself. Similarly, the activation energy of the interaction of Al-Fe is less than that of Al-Mo. The critical temperature $\mathrm{T}_{0}$ is much greater than the die temperature. Therefore the soldering resistant ability can be obtained by laser melted molybdenum coating on the die surface.

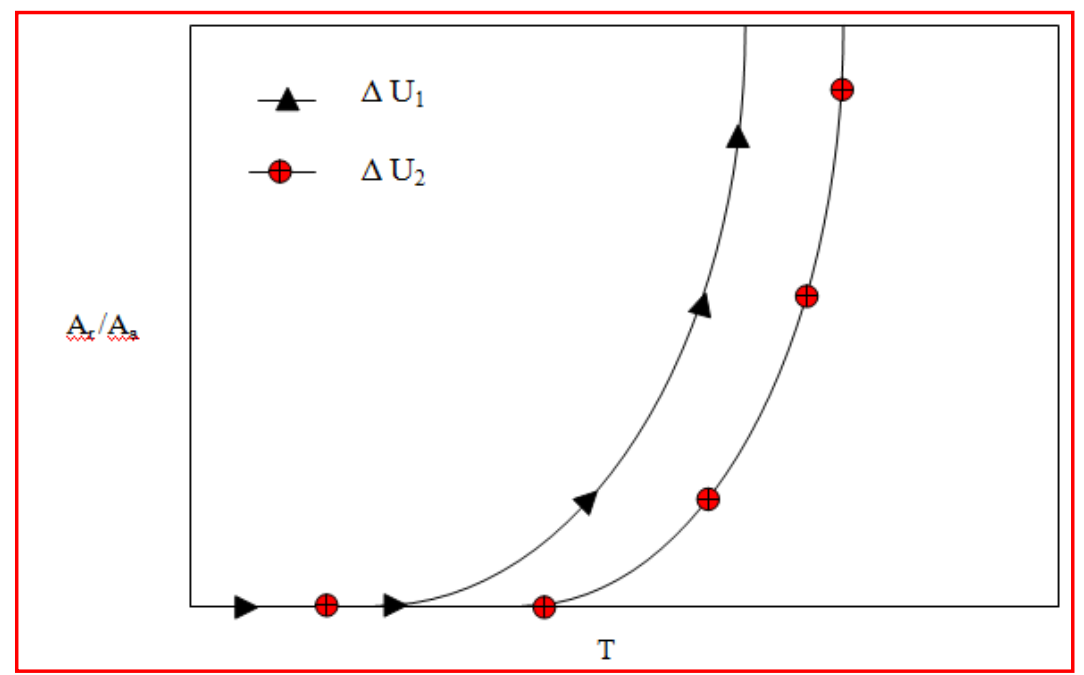

Figure 4. Effect of temperature $(T)$ and activation energy $(\Delta U)$ on $A_{r} / A_{a}$.

It is observed from Figure 4. The interfacial temperature is vital factor that influences the value of $A_{r} / A_{a}$. At starting, the value of $A_{r} / A_{a}$ is small with respect to temperature $(T)$. However, when the temperature increases to meet the critical temperature $T_{0}$, the value of $\mathrm{A}_{\mathrm{r}} / \mathrm{A}_{\mathrm{a}}$ increases suddenly. The temperatures of both the die surface and the interface depend on liquid metal pouring temperature and the heat transfer condition. The soldering occurs rarely, when the die temperature is low. Soldering occurs easily at hot spots, where the die temperature is very high. This has been verified during casting process.

Injection pressure is one more factor that aggravates the soldering formation. The effects of injection pressure on soldering occurances include two parts namely chemical action and mechanical action. High pressure and velocity of injected molten metal on to the die surface causes partial wash out of coating material on the die surface. This result in direct attack of molten metal with die steel surface. The mechanical action of injection pressure increases the value of $\mathrm{A}_{\mathrm{r}} / \mathrm{A}_{\mathrm{a}}$. High injection pressure increases the alloy energy and the number of active atoms that causes soldering formation. Therefore the value of $\mathrm{A}_{\mathrm{r}} / \mathrm{A}_{\mathrm{a}}$ rises with the chemical action of the injection pressure.

Figure 5. Demonstrates the effect of injection pressure on $A_{r} / A_{a}$ where $P_{2}$ is two times as greater as $P_{1}$. It is evident that the value of $A_{\mathrm{r}} / \mathrm{A}_{\mathrm{a}}$ is more at high pressure at the same temperature. So die soldering occurs very easily under high injection pressure.

The wetting process of liquid metal happens on the die surface due to surface tension, when the liquid metal is injected in to the die cavity. The wettability is always demonstrated by contact angle $\theta$. The wettability is perfect, when the contact angle is zero. However, the solid surface is completely dry, when the contact angle is $180^{\circ}$. The solid surface is partially wetted, if the contact angle is in between $0-180^{\circ}$. The smaller contact angle results in better wetting. The value of contact angle between the die steel surface and the liquid aluminum represents the soldering tendency of the aluminum with the steel die. 


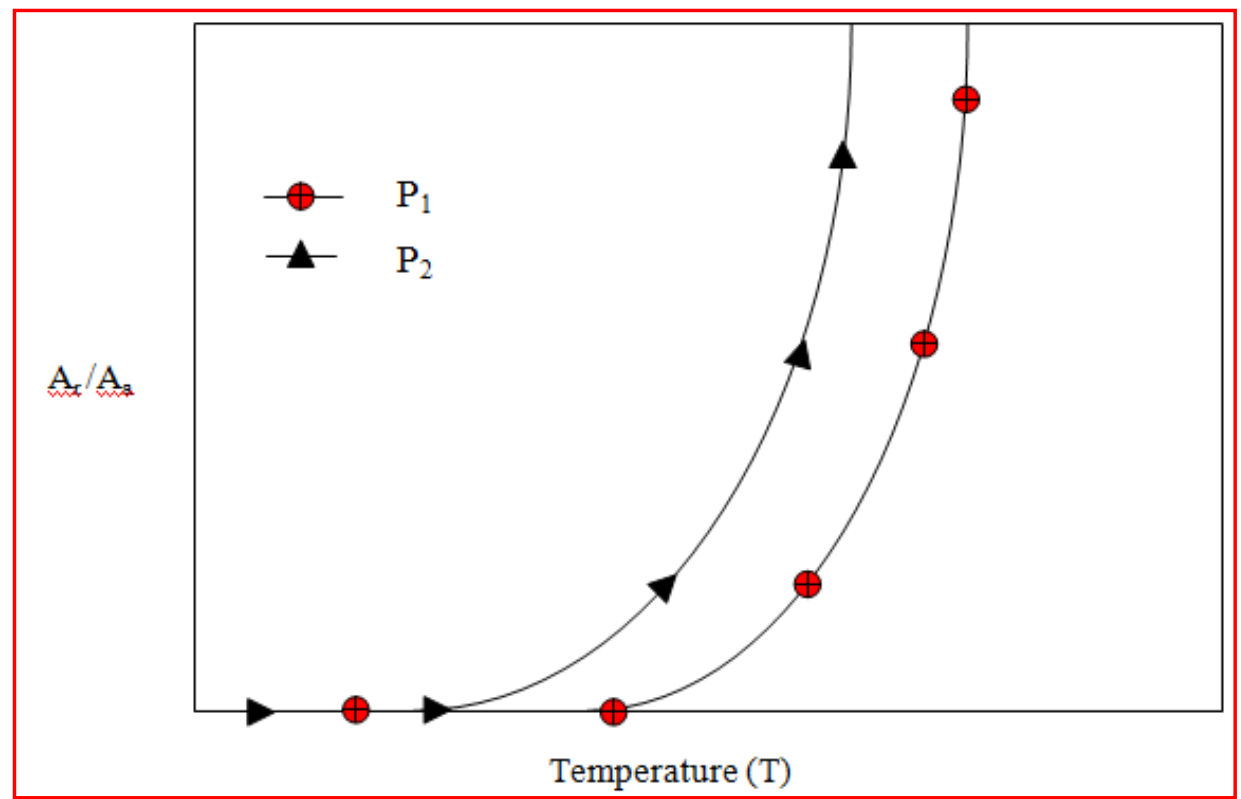

Figure 5. depicts effect of injection pressure on the value of $\mathrm{A}_{\mathrm{r}} / \mathrm{A}_{\mathrm{a}}$.

In aluminum die casting, there is a contact angle hysteresis between the die surface and the molten aluminum. The major factors that affects hysteresis contact angle are solute deposition on the die surface, surface roughness and molten metal. A contamination point still exists, even if the die lubricant is partially washed out from the die surface. It has been experimented (39) (40) that the influence of surface contamination on the contact angle hysteresis is equal to that of a rough surface. The contact angle hysteresis of a random rough surface of the die by molten aluminum metal and the wettability is discussed here. The roughness coefficient (r) for the rough surface is defined as the ratio of the real contact area to the apparent projective area. The relation between the apparent contact angle $\theta_{\mathrm{a}}$ and the real contact angle $\theta_{\mathrm{e}}$ is given by Wenzel as:

$\operatorname{Cos} \theta_{\mathrm{r}}=\mathrm{r} \operatorname{Cos} \theta_{\mathrm{a}}$

(10).

A rough surface consists of small pieces of different materials is consider as a compound surface. By assuming that the die compound surface consists of two kinds of flat surfaces with the fractions to the apparent projected area are $\mathrm{f} 1$ and $\mathrm{f} 2$ respectively. The apparent contact angle is expressed as:

$\operatorname{Cos} \theta_{\mathrm{C}}=\mathrm{f} 1 \operatorname{Cos} \theta_{1}+\mathrm{f} 2 \operatorname{Cos} \theta_{2}$

Where $\theta_{1}$ and $\theta_{2}$ are the real contact between the two kinds of flats and the liquid. Gas always obstructs the large size holes on the die steel surface by the liquid aluminum metal. This cannot occur by the smaller size holes on the die surface due to surface tension. If $\mathrm{f} 2$ is the fraction that cannot contact with the molten aluminum, $\theta_{2}$ is equal to $180^{\circ}$ and the expression changes into the following form:

$\operatorname{Cos} \theta_{\mathrm{C}}=\mathrm{f} 1 \operatorname{Cos} \theta_{1} \mathrm{f} 2$ and considering $\mathrm{f} 2=1-\mathrm{f} 1$, the equation can be obtained as:

$\operatorname{Cos} \theta_{\mathrm{r}}=\mathrm{rfl} \operatorname{Cos} \theta_{1}+\mathrm{f} 1-1$

When $\mathrm{f} 1=1$, that is the die surface contacts with liquid aluminum perfectly without obstructing gas, the result of the surface roughness on the apparent contact angle between the iron and the liquid aluminum or WC-Co and the molten aluminum is depicts in Figure 6(a). If $\mathrm{f} 1=0.8$, when the liquid aluminum obstructs gas on large size valleys, the relation between the surface roughness of the two contact systems and the apparent contact angle is depicts in Figure 6(b). The apparent contact angle is less than $90^{\circ}$, when the die contacts with the liquid aluminum. It is observed that the apparent contact angle decreases with increase in the surface roughness coefficient. The apparent contact angle between WC-Co and liquid aluminum is more than $90^{\circ}$ and increases with increase in the surface 
roughness coefficient. However the soldering tendency with WC-Co coated die is less than when compared to steel die.

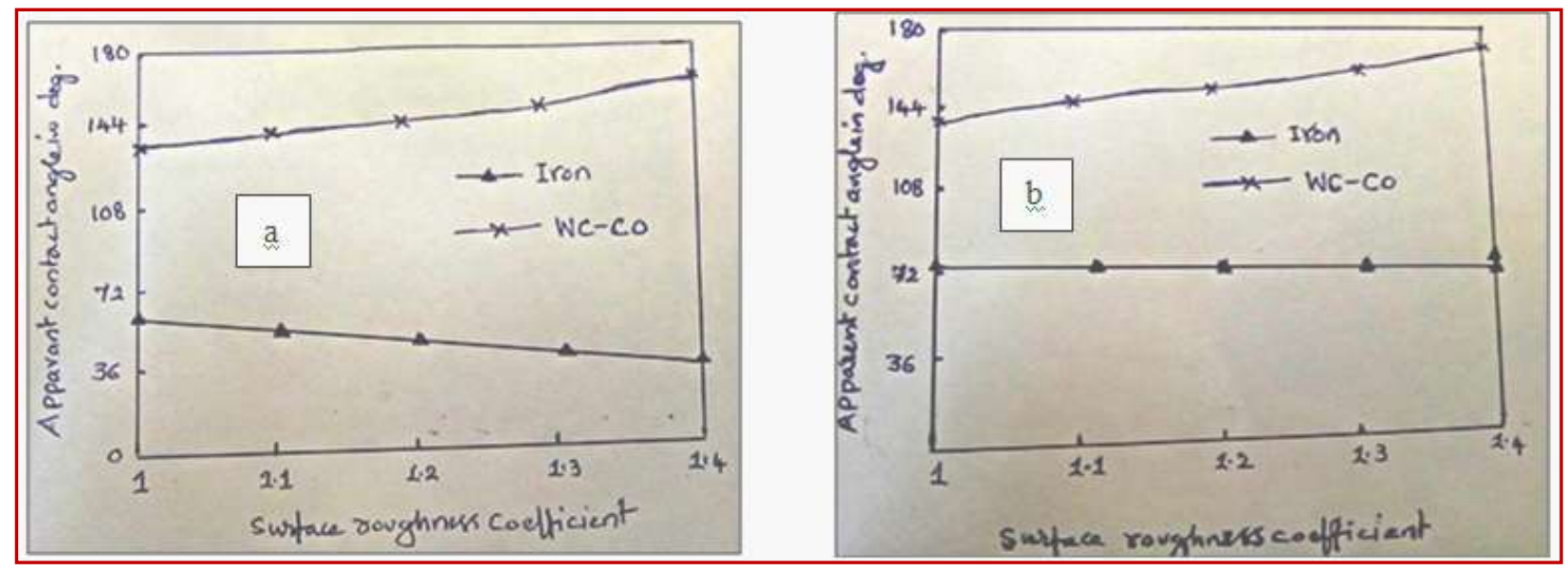

Figure 6.Apparent contact angle between solid surface and aluminum melt vs. surface roughness coefficient: (a) $\mathrm{f} 1=1$; (b) $\mathrm{f} 2=0.8$.

Comparing Figure 6 (a) and (b), It is noticed that the apparent contact angle of obstructing gas is higher than that of full contact even though the roughness coefficients are the same. This demonstrates that the contact angle hysteresis increase with increasing number of micro cavities and micro holes on the die steel surface.

An experiment is conducted in the die casting plant with high gate velocity of $150 \mathrm{~m} / \mathrm{sec}$ and high pouring metal temperature of $750^{\circ} \mathrm{C}$. In this experiment soldering takes place after only one or two shots to $\mathrm{H} 13$ steel die without any coating and die lubrication agent. This reveals that the interfacial temperature is very near to the critical temperature $\mathrm{T}_{0}$. This causes strong chemical reaction between the steel die surface and molten metal. The soldering occurs after second shot due to the oxide films on the die surface have been washed out by the first shot. But in actual practice, the gate velocity, pouring molten temperature and the die temperature is lower and die is also protected by die lubricant which form thin layer on die surface. This thin layer acts as barrier between the die surface and molten metal and thus prevents occurrence of die soldering. On the other hand, if there is any hot spot in the die, the lubricant layer is detached / washed off from the die and causes direct contact of molten metal with die surface. This results in die soldering formation. This is demonstrated in the Figure 7. At the beginning no soldering occurs at the die surface. As the number of casting cycles keeps on increasing, the aluminum atoms from the liquid metal diffuses into the die surface and the iron atoms from the die dissolves in the melt. The aluminum atoms concentration on the die slowly increases. When it reaches a threshold value, chemical reaction will occur between the die and molten metal and leads to soldering. An intermetallic compounds are formed and grown, which are washed out by high pressure of molten metal. Micro cavities and micro holes are formed and grown by erosion of the liquid metal. With the continuation of die casting process, heat checks are formed on the die which results in mixed soldering. This heat checks grows and leads to crack propagation. This crack propagation causes die failure and finally withdrawn from the production service.

The formation and spread of soldering in the die with protective coating is different from the die without protective coating. Figure 8 . Demonstrates the condition of the die with protective coating. The coating is so strong and cannot be washed out easily with the injection pressure of the metal. According to energy analysis [18] the chemical reaction between the molten metal and the die with coating is very low and hence the tendency of soldering formation is very low or nil. However with increasing casting cycles, micro cracks are produced in the coating. Once these cracks are propagated into the die, the coating detached from the die. This result in the die cannot be used for further production and finally withdrawn from the service. 


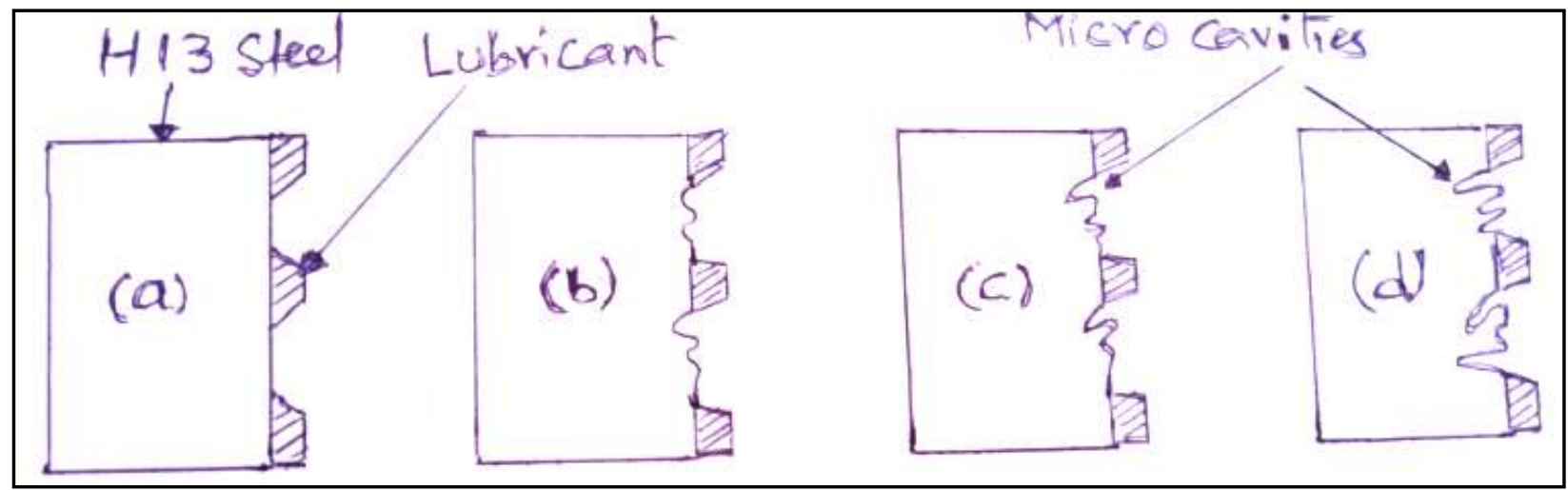

Figure 7. Shows the surface state change of the die without die coatings (PVD) in die casting process.
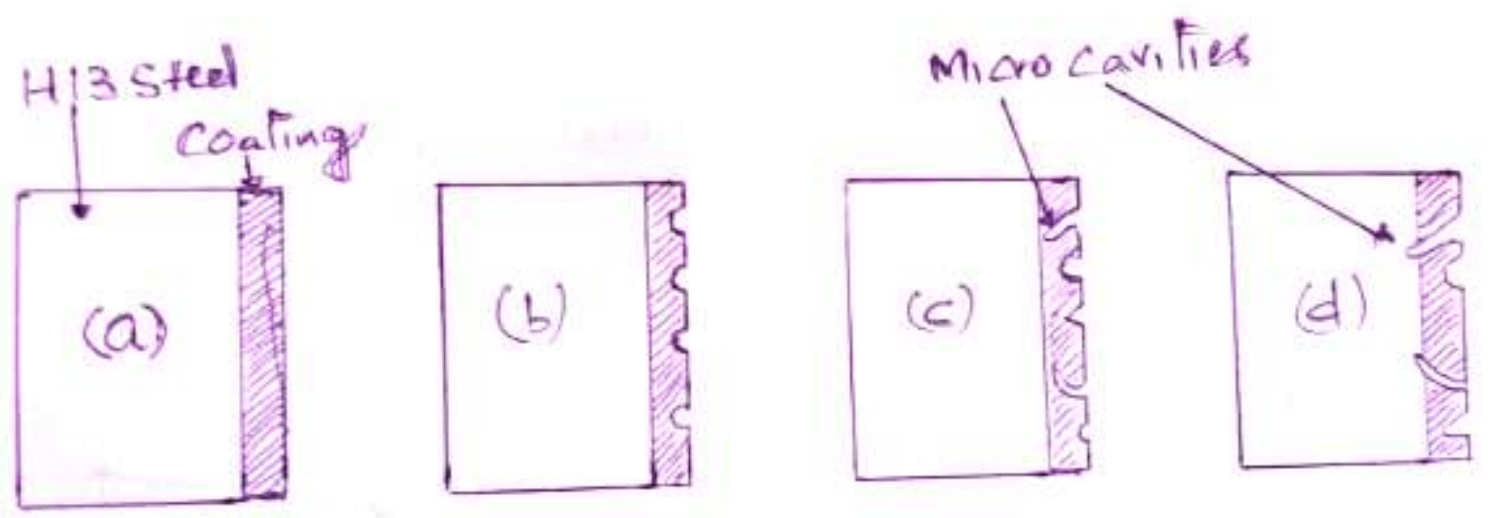

Figure 8. Shows the die surface state with coatings (PVD) in die casting process.

\section{Conclusions:}

- Large number of micro cavities, micro holes, micro cracks are observed at soldering portion of the die steel surface. These surface imperfections are responsible for mechanical action between the molten metal and the die and causes chemical reaction at the given apparent contact area.

- Soldering is grouped into three types namely mechanical, physico-mechanical and mixed soldering based on mechanism of soldering.

- The activation energy of interaction between the die and the casting and the interfacial temperature strongly influence the value of $A_{r} / A_{a}$.

- Die with special protective coatings are less affinity to soldering formation.

- The roughness coefficient of the die surface increases w.r.t increase in number of casting cycles. This results in decrease in the apparent contact angle between the die and the liquid metal.

\section{Declarations:}

- List of abbreviations:

Not applicable

- Availability of data and materials 
Not applicable

- Competing interests

Not applicable

- Authors contributions

M.Bhaskar- carried out original work

Tamil Nalluswamy- editing and drafting

\section{Acknowledgements:}

The authors acknowledges the Sundaram Clayton high pressure die casting foundry management and staff for their continuous support extended throughout this work. The author doesn't receive funding from any source for carrying out this research work.

\section{References:}

\section{Bibliography}

1. Increasing the lifespan of high-pressure die cast molds subjected to severe wear. Nunes, V., et al. 2017, Surface and Coatings Technology, Vol. 332, pp. 319-331. The 44th International Conference on Metallurgical Coatings andThin Films (ICMCTF). ISSN: 0257-8972.

2. Computer modeling and prediction of thermal fatigue cracking in die-casting tooling. Srivastava, A., Joshi, V. and Shivpuri, R. 2004, Wear, Vol. 256, pp. 38-43. ISSN: 0043-1648.

3. Method to evaluate the adhesion behavior of aluminum-based alloys on various materials and coatings for lube-free die casting. Wang, Bo, et al. 2016, Journal of Materials Processing Technology, Vol. 237, pp. 386-393. ISSN: 0924-0136.

4. Effect of aluminizing and oxidation on the thermal fatigue damage of hot work tool steels for high pressure die casting applications. Salem, M., et al. 2019, International Journal of Fatigue, Vol. 119, pp. 126-138. ISSN: 0142-1123.

5. Development of a method for assessing erosive wear damage on dies used in aluminium casting. Mohammed, A., Marshall, M. B. and Lewis, R. 2015, Wear, Vols. 332-333, pp. 1215-1224. 20th International Conference on Wear of Materials. ISSN: 0043-1648.

6. Failure analysis of shot-sleeves used in brass high pressure die-casting process. Abid, Dorra, et al. 2019, Engineering Failure Analysis, Vol. 104, pp. 177-188. ISSN: 1350-6307.

7. CrN/AIN and CrN/AIN/AI2O3 coatings deposited by pulsed cathodic arc for aluminum die casting applications. Bobzin, K., et al. 2015, Surface and Coatings Technology, Vol. 284, pp. 222-229. The 42nd International Conference on Metallurgical Coatings and Thin Films. ISSN: 0257-8972.

8. Analysis of CrN/AIN/AI2O3 and two industrially used coatings deposited on die casting cores after application in an aluminum die casting machine. Bobzin, K., et al. 2016, Surface and Coatings 
Technology, Vol. 308, pp. 374-382. The 43rd International Conference on Metallurgical Coatings and Thin Films. ISSN: 0257-8972.

9. Energy-based approach to thermal fatigue life of tool steels for die casting dies. Chen, Changrong, et al. 2016, International Journal of Fatigue, Vol. 92, pp. 166-178. ISSN: 0142-1123.

10. Die erosion and its effect on soldering formation in high pressure die casting of aluminium alloys. Chen, Z. W. and Jahedi, M. Z. 1999, Materials \& Design, Vol. 20, pp. 303-309. ISSN: 0261-3069.

11. Failure analysis of H13 steel die for high pressure die casting Al alloy. Ding, Rengen, et al. 2021, Engineering Failure Analysis, Vol. 124, p. 105330. ISSN: 1350-6307.

12. Modeling of high temperature- and diffusion-controlled die soldering in aluminum high pressure die casting. Domkin, K., Hattel, J. H. and Thorborg, J. 2009, Journal of Materials Processing Technology, Vol. 209, pp. 4051-4061. ISSN: 0924-0136.

13. Performance evaluation of PVD coatings for high pressure die casting. Gulizia, S., Jahedi, M. Z. and Doyle, E. D. 2001, Surface and Coatings Technology, Vol. 140, pp. 200-205. ISSN: 0257-8972.

14. Evaluation of soldering, washout and thermal fatigue resistance of advanced metal materials for aluminum die-casting dies. Zhu, Yulong, et al. 2004, Materials Science and Engineering: A, Vol. 379, pp. 420-431. ISSN: 0921-5093.

15. Hard coatings produced by PACVD applied to aluminium die casting. Heim, D., Holler, F. and Mitterer, C. 1999, Surface and Coatings Technology, Vols. 116-119, pp. 530-536. ISSN: 0257-8972.

16. Dissolution and soldering behavior of nitrided hot working steel with multilayer LAFAD PVD coatings. Joshi, V., et al. 2001, Surface and Coatings Technology, Vols. 146-147, pp. 338-343. Proceedings of the 28th International Conference on Metallurgic Coatings and Thin Films. ISSN: 0257-8972.

17. Investigating ion nitriding for the reduction of dissolution and soldering in die-casting shot sleeves. Joshi, Vivek, et al. 2003, Surface and Coatings Technology, Vols. 163-164, pp. 668-673. Proceedings of the 29th International conference on Metallurgical Coatings and Thin Films. ISSN: 0257-8972.

18. Failure modes in field-tested brass die casting dies. Persson, Anders, Hogmark, Sture and Bergström, Jens. 2004, Journal of Materials Processing Technology, Vol. 148, pp. 108-118. ISSN: 0924-0136.

19. Study of protective coatings for aluminum die casting molds. Peter, Ildiko, Rosso, Mario and Gobber, Federico Simone. 2015, Applied Surface Science, Vol. 358, pp. 563-571. 9th International Conference on Materials Science \& Engineering [BraMat 2015]. ISSN: 0169-4332.

20. Formation and progression of die soldering during high pressure die casting. Chen, Z. W. 2005, Materials Science and Engineering: A, Vol. 397, pp. 356-369. ISSN: 0921-5093.

21. Erosion process analysis of die-casting inserts for magnesium alloy components. Hou, Li-feng, et al. 2013, Engineering Failure Analysis, Vol. 33, pp. 457-464. ISSN: 1350-6307. 
22. Failure analysis of die casting pins for an aluminum engine block. Kang, Se-Hyung, et al. 2019, Engineering Failure Analysis, Vol. 104, pp. 690-703. ISSN: 1350-6307.

23. Experimental and numerical analysis of failures on a die insert for high pressure die casting.

Markežič, R., et al. 2019, Engineering Failure Analysis, Vol. 95, pp. 171-180. ISSN: 1350-6307.

24. Analysis of degradation processes on shot sleeves made from new Si-Mo cast iron in aluminium high pressure die casting - A case study. Mitrović, Danijel, et al. 2020, Engineering Failure Analysis, Vol. 109, p. 104283. ISSN: $1350-6307$.

25. Experimental study and theoretical analysis on die soldering in aluminum die casting. Zhu, Hanliang, Guo, Jingjie and Jia, Jun. 2002, Journal of Materials Processing Technology, Vol. 123, pp. 229-235. ISSN: 0924-0136.

26. Characterization of spray lubricants for the high pressure die casting processes. Sabau, Adrian S. and Dinwiddie, Ralph B. 2008, Journal of Materials Processing Technology, Vol. 195, pp. 267-274. ISSN: 0924-0136.

27. A study of PVD coatings and die materials for extended die-casting die life. Wang, Yucong. 1997, Surface and Coatings Technology, Vols. 94-95, pp. 60-63. 24th International Conference on Metallurgical Coatings and Thin Films. ISSN: 0257-8972.

28. Dissolution and erosion behavior of AISI H13 shot sleeve in high pressure die casting process. Vachhani, H., Rathod, M. and Shah, R. 2019, Engineering Failure Analysis, Vol. 101, pp. 206-214. ISSN: 1350-6307.

29. Improved ejection test for evaluation of soldering tendency of cast alloy to die core materials. Terek, Pal, et al. 2019, Journal of Materials Processing Technology, Vol. 266, pp. 114-124. ISSN: 0924-0136.

30. Soldering mechanisms in materials and coatings for aluminum die casting. Tentardini, Eduardo K., et al. 2008, Surface and Coatings Technology, Vol. 202, pp. 3764-3771. ISSN: 0257-8972.

31. Optimization of plasma-assisted chemical vapour deposition hard coatings for their application in aluminium die-casting. Mitterer, C., et al. 2001, Surface and Coatings Technology, Vols. 142-144, pp. 1005-1011. Proceedings of the 7th International Conference on Plasma Surface Engineering. ISSN: 02578972.

32. Application of hard coatings in aluminium die casting - soldering, erosion and thermal fatigue behaviour. Mitterer, C., et al. 2000, Surface and Coatings Technology, Vol. 125, pp. 233-239. ISSN: 02578972.

33. Effects of die core treatments and surface finishes on the sticking and galling tendency of Al-Si alloy casting during ejection. Terek, Pal, et al. 2016, Wear, Vols. 356-357, pp. 122-134. ISSN: 0043-1648.

34. Thermo fatigue cracking of die casting dies. Klobčar, D., et al. 2012, Engineering Failure Analysis, Vol. 20, pp. 43-53. ISSN: 1350-6307. 
35. Development of cermet coatings by kinetic spray technology for the application of die-soldering and erosion resistance. Khan, Faisal Farooq, et al. 2009, Surface and Coatings Technology, Vol. 204, pp. 345352. ISSN: 0257-8972.

36. Thermal fatigue of materials for die-casting tooling. Klobčar, D., Tušek, J. and Taljat, B. 2008, Materials Science and Engineering: A, Vol. 472, pp. 198-207. ISSN: 0921-5093.

37. Design methodology for optimized die coatings: The case for aluminum pressure die-casting: Invited paper B7-1-1, ICMCTF, presented Monday May 2nd, 2005, San Diego. Lin, J., et al. 2006, Surface and Coatings Technology, Vol. 201, pp. 2930-2941. ISSN: 0257-8972.

38. Thermal stresses in aluminium alloy die casting dies. Klobčar, Damjan and Tušek, Janez. 2008, Computational Materials Science, Vol. 43, pp. 1147-1154. ISSN: 0927-0256.

39. A new fatigue life model for thermally-induced cracking in $\mathrm{H} 13$ steel dies for die casting. Lu, Yan, et al. 2019, Journal of Materials Processing Technology, Vol. 271, pp. 444-454. ISSN: 0924-0136.

40. Thermal fatigue failure of brass die-casting dies. Mellouli, Dhouha, et al. 2012, Engineering Failure Analysis, Vol. 20, pp. 137-146. ISSN: 1350-6307. 
Figures
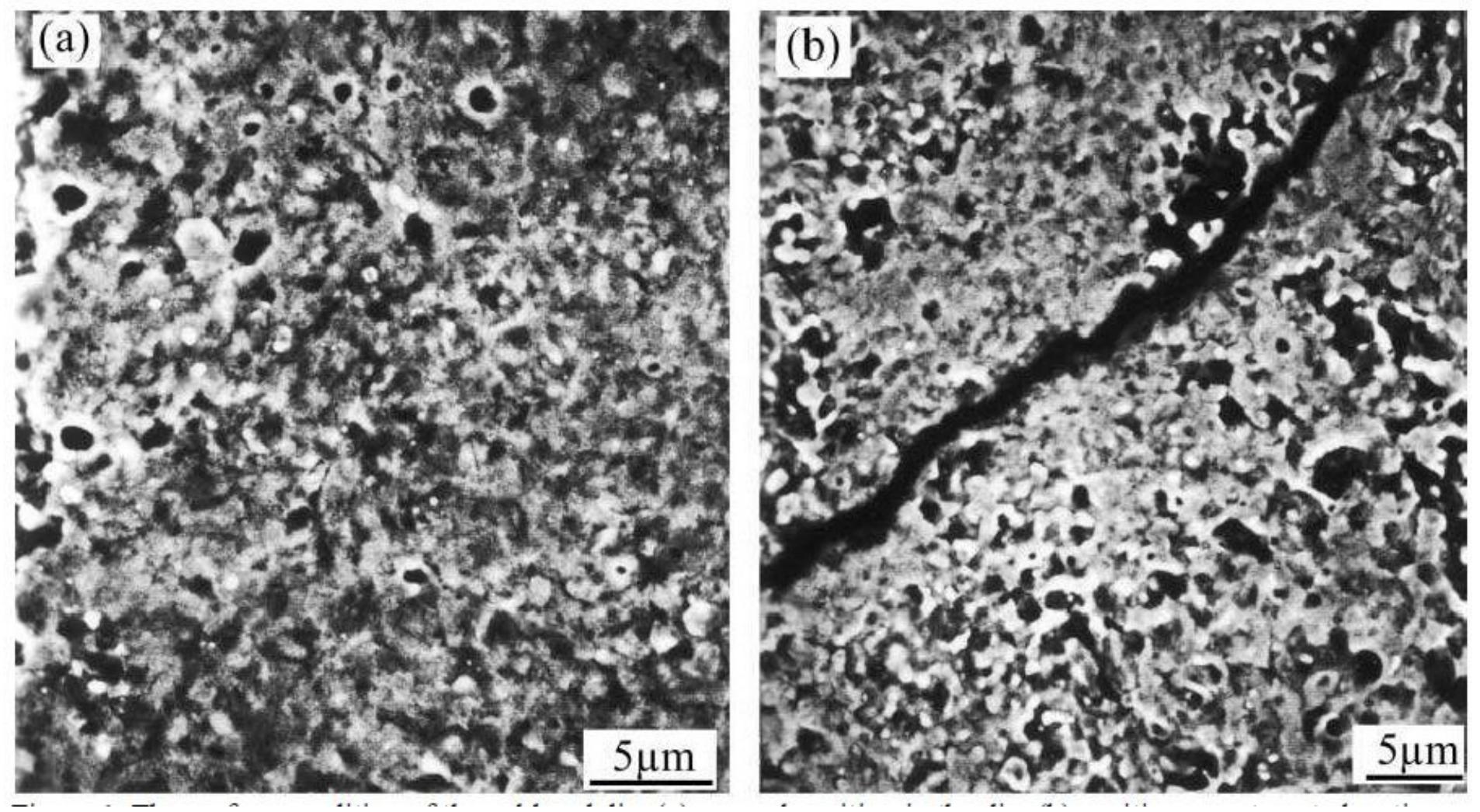

Figure 1

The surface condition of the soldered die: (a) general position in the die: (b) position near to gate location.
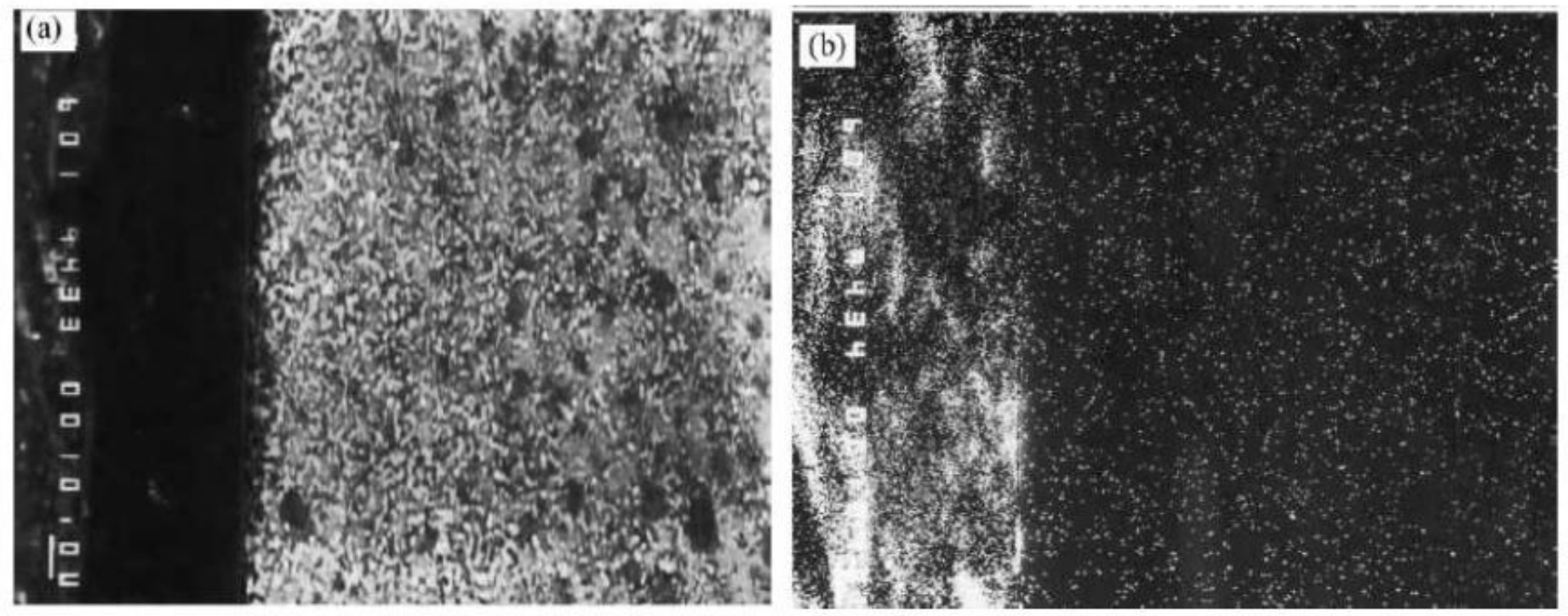

Figure 2

SEM analysis of physico- chemical soldering: (a) back scattered electron image (b) X-ray mapping of Al. 

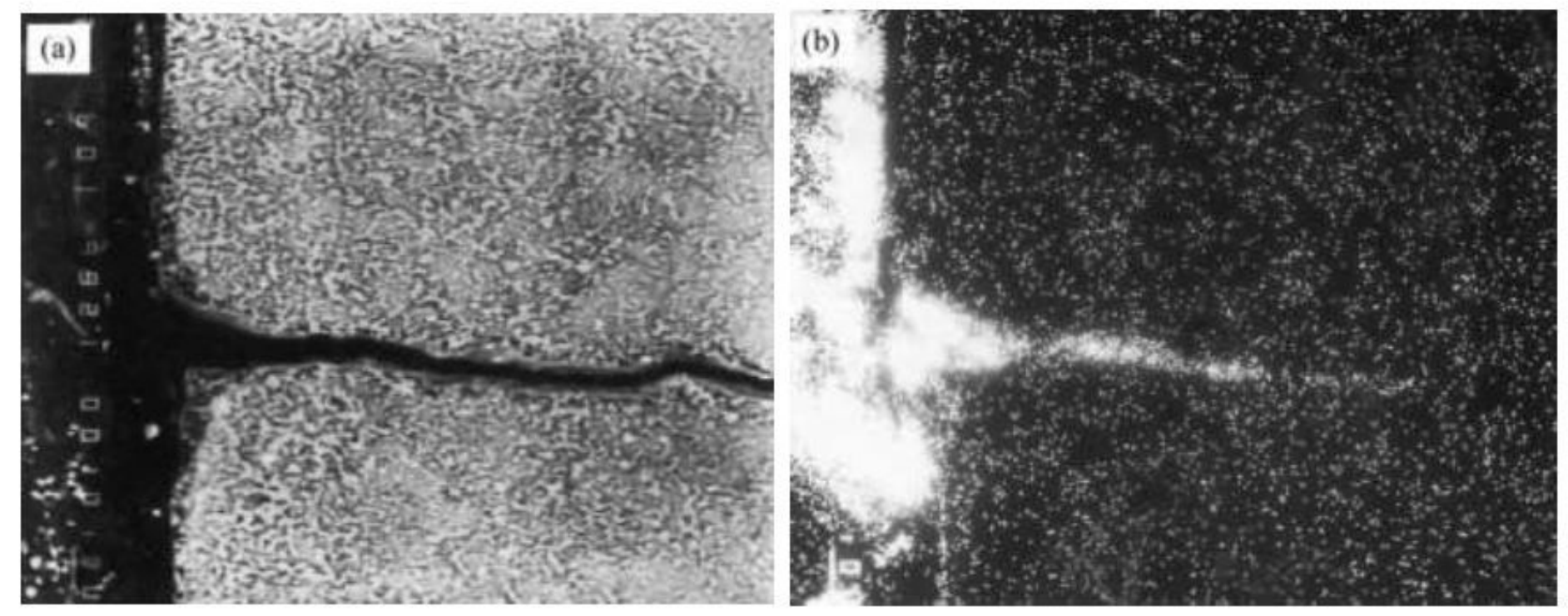

Figure 3

SEM analysis of Mechanical soldering: (a) back-scattered electron image: (b) X-ray mapping of Al.

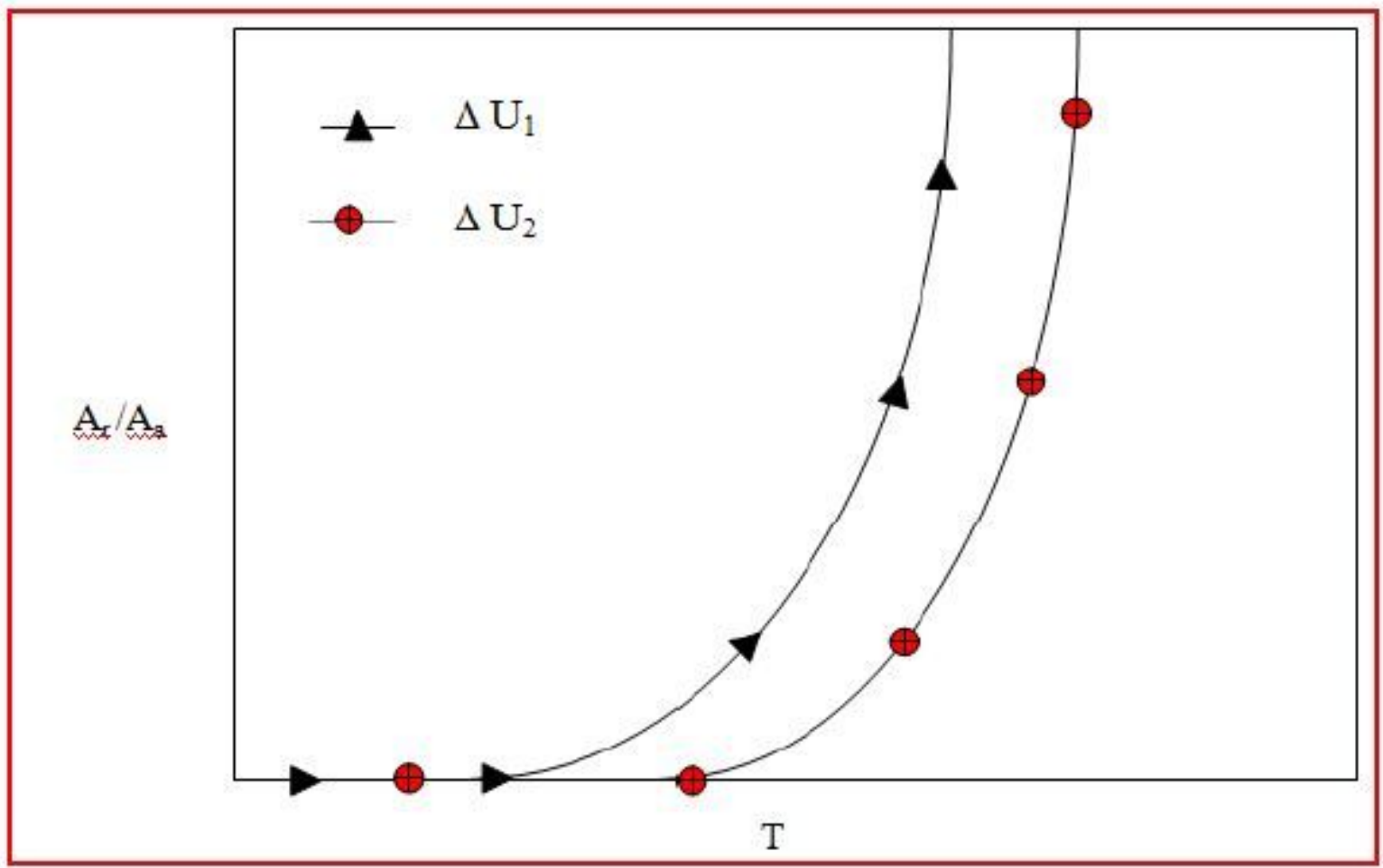

Figure 4

Effect of temperature $(T)$ and activation energy $(\Delta U)$ on $\operatorname{Ar} / A a$. 


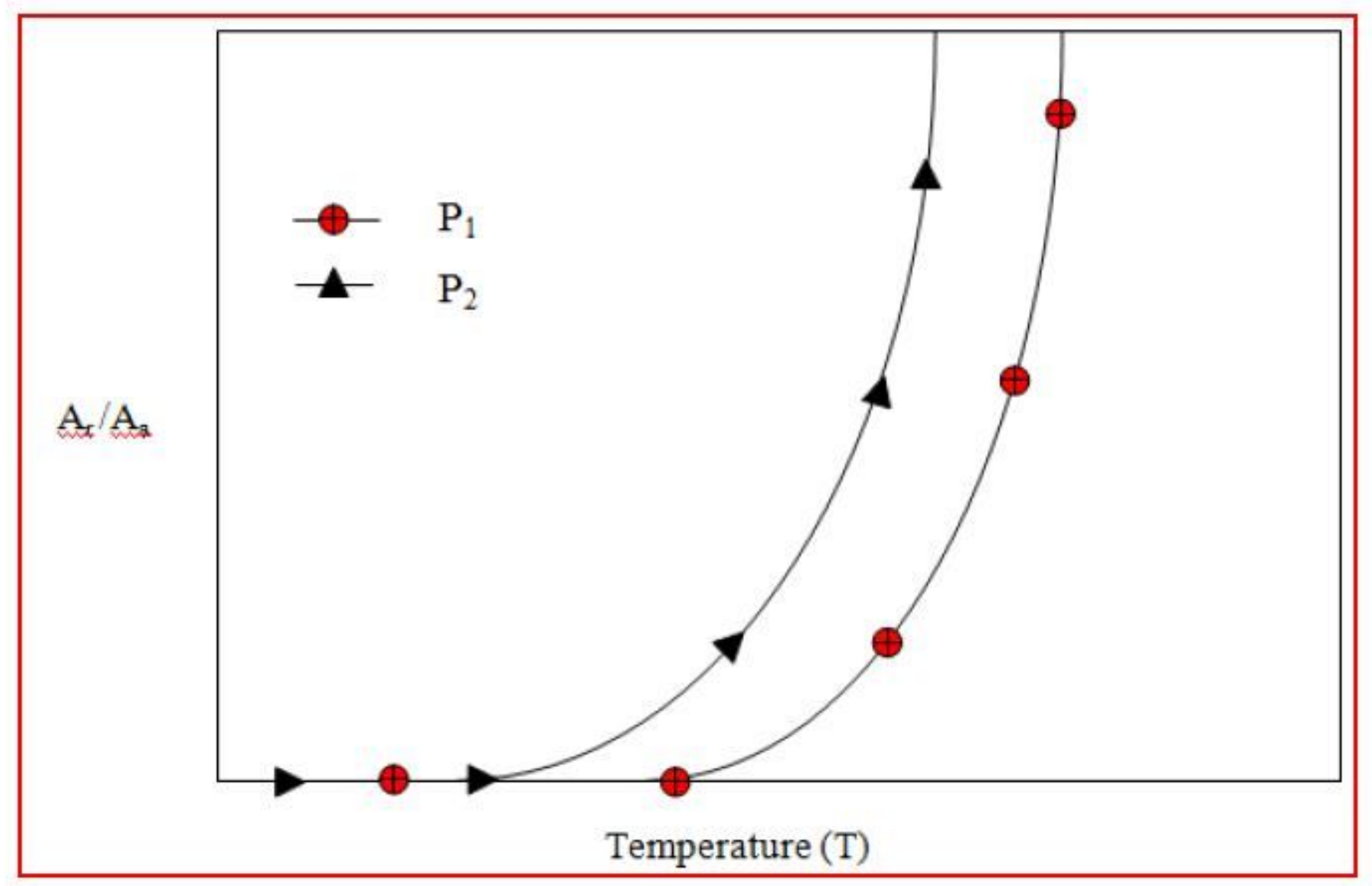

Figure 5

depicts effect of injection pressure on the value of $\mathrm{Ar} / \mathrm{Aa}$.

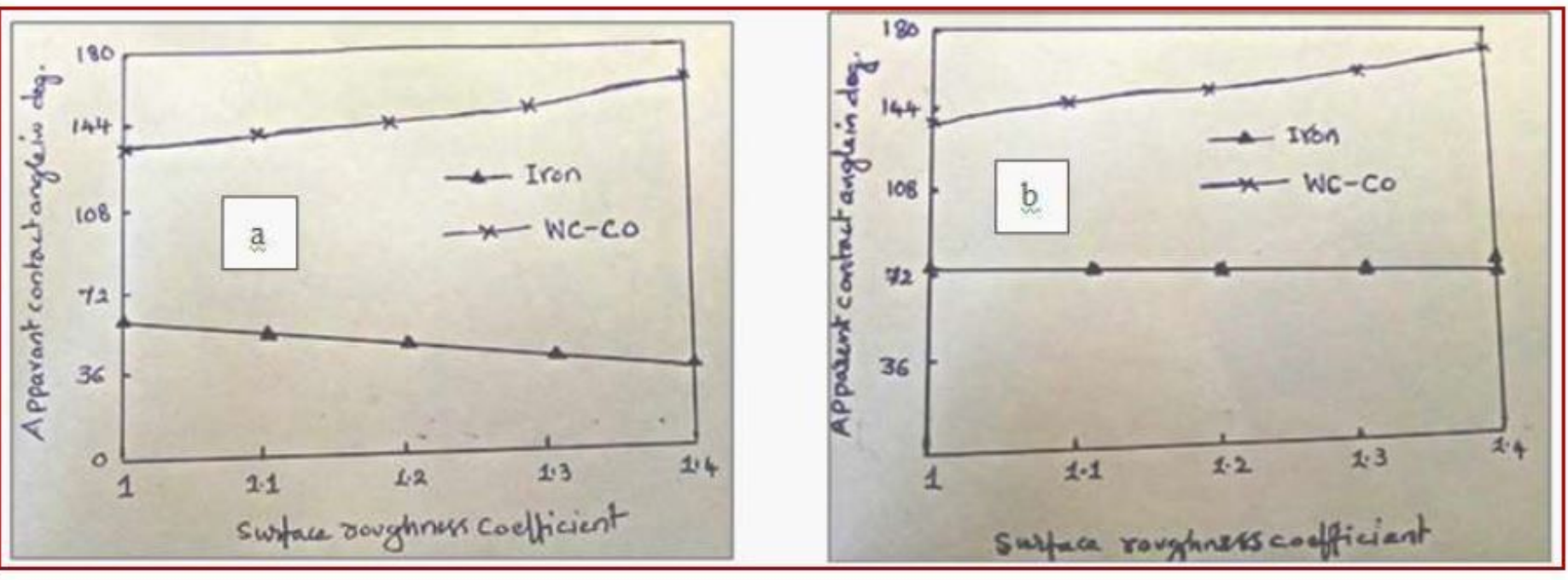

Figure 6

Apparent contact angle between solid surface and aluminum melt vs. surface roughness coefficient: (a) $\mathrm{f} 1=1 ;$ (b) $\mathrm{f} 2=0.8$. 


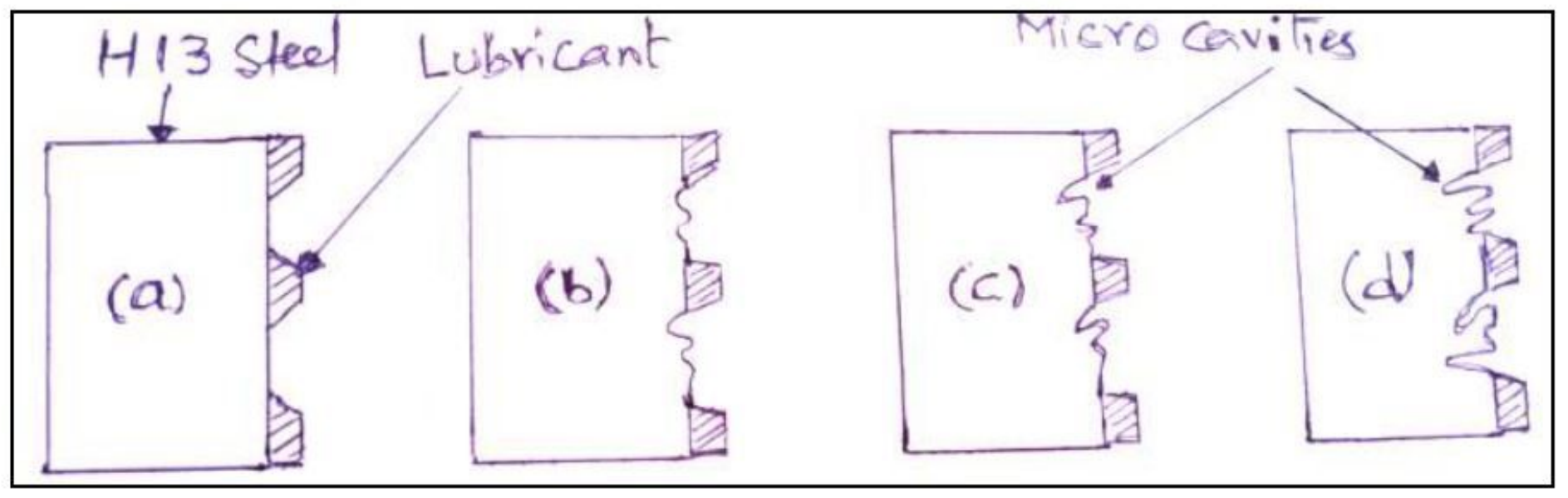

Figure 7

Shows the surface state change of the die without die coatings (PVD) in die casting process.

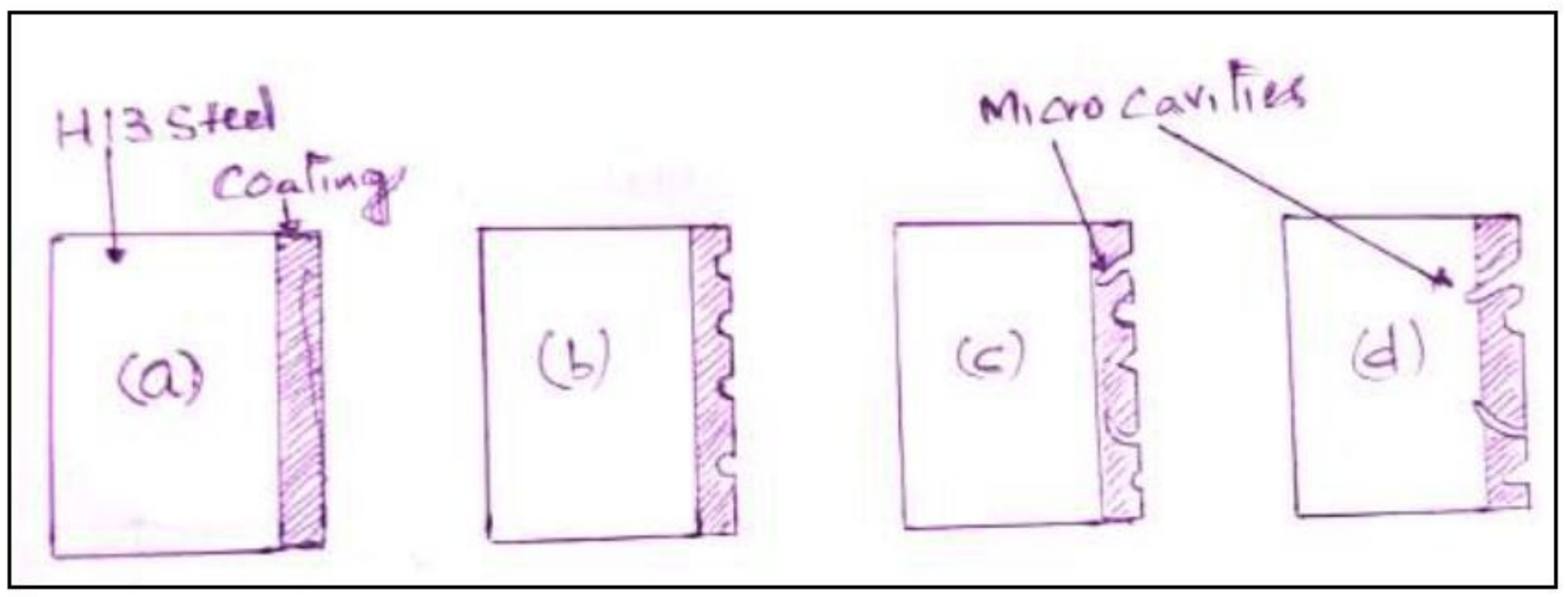

Figure 8

Shows the die surface state with coatings (PVD) in die casting process. 